Dr. WiLlis Ms informed the Society, that he had within a few days been informed by a northern medical professor, that he was in the constant habit of prescribing drachm doses of the tincture of digitalis, and that in one instance he had known of one fluid ounce having been taken, without producing any unpleasant effect.

On this subject Dr. Clutrerbuck remarked, that the effects of digitalis are very uncertain; he himself had often prescribed drachm doses of the tincture; in some instances they had failed in producing any effect, whilst in other cases, very unpleasant symptoms ensued. Dr. Clutterbuck further said, that the tartar emetic was equally uncertain in its effects on the animal economy; in some cases, one-eighth of a grain producing much sickness, whilst in others he had given four or five grains, with no sensible effect.

[It was announced that Mr. Lambert would, at the ensuing meeting, submit some observations to the Society, in reference to the operation of dividing the vas deferens, as a substitute for castration.]

ON THE TREATMENT OF HYDROPHOBIA.

\section{To the Editor of The Lavcet.}

Sir,-Being assured that any suggestions, however simple, so far as they are well meant towards the alleviation of suffering humanity, will not be deemed altogether unworthy the notice of your professional readers, I am encouraged to lay before them a few remaris on the curative treatment of that most dreadful disease, hydrophobia. 'Though it is a subject which has occupied the attentive consideration of many of the intelligent members of the profession in all ages, and none more especially than those of the present age, yet we have to lament our total inadequacy to avert its awful fatality ; and, hence, I feel some degree of diffidence in entering upon it the subject.

It is true that the prophylactic treatment, when timely and properly practised,

trial, that the medicines failed in effecting the intended object, and that it was at length accomplished by mechanical violence. In consequence of the defective state of the law, which has made no provision in respect to manual operations, the criminal was tried for giving medicine which had no effect, whilst the means by which the crime had actually been perpetrated, were only ad. mitted in evidence as proof of the intention with which the medicines were given! has generally been successful; but I am not aware of a single instance of a cure being performed when the disease has evidently arisen from the bite of a truly rabid animal, and the constitutional symptoms have become unequivocally formed. Respecting the nature of hydrophobia, I would define it to be a morbid sensibility of the nervous system, occasioned by the application of the saliva (or the specific virus mixed with it) of a rabid animal directly to the nerves of the injured part, producing, by its continuance, more or less inflammation in some of the internal parts of the body.

The dread of water which is said, though erroneously, to be peculiar to bydrophobic patients, appears to depend upon the morbid excitement of the nerves of the pharynx and larynx; giving rise, at each attempt to swallow, to the most violent contractions of those parts, and, sympathetically, of the lower part of the osophagus and cardiac extremity of the stomach; thereby producing a distressing sense of suffocation and consequent convulsive action of the whole system.

That the dread expressed is of the act of swallowing, and not of the water, is proved by the fact that the sight or noise of any liquid with which the idea of deglutition is associated is sufficient, in many cases, to excite a paroxysm, whereas the rattling of the urine produces not the slightest uneasiness. Again, some patients will carry a cup of water to the lips with tolerable com. posure, but as soon as the muscles of deglutition are called into action by an attempt to drink, the whole system is threatened with convulsions, and the resolution fails. It is unnecessary for me to take up your time in speaking of the remedies now generally employed in the cure of this disease; but, in addition to them, I propose the antimonium tartarizatum as a medicine which I think, from an a priori consideration of its properties, very likely to be useful. I would give it as soon as the constitutional symptoms were anticipated, in such doses as to produce complete nausea, and consequent relaxation of the system; during which state the operations of the mind are in some degree suspended, a circumstance much to be wished for. How long this state should be kept up, I am not prepared exactly to say; but I should suppose there would be little danger of a recurrence of the paroxysms after an interval of from 12 to 24 hours. At the end of this time, if the treatment proved successful so far, I would diminish the dose of the tartar emetic, and combine with it, small doses of calomel and opium, so as to promote its action more especially on the skin and mucous membranes. The submurias hydrargyri might be continued, in this way, to the extent of producing a slight sa- 
livation, which might be kept up for a few days with advantage. It has been snid that if salivation would answer, the disease would cure itself, since a pretty copious flow of saliva is almost a constant symptom; this, however, I am inclined to think, does not depend upon any great increase: of saliva; but, rather, upon the patient's inability to swallow it as ordinarily. 'The depressing plan having been pursued as far as was deemed sufficient, the tone of the system might be restored by the administration of the spts. ammon. arom., with small doses of the tinctura opii; and, subse. quently, full doses of the sulphate of quinine, The bowels should, of course, be carefully attended to during the whole course of the disease. Should the constitutional symp. toms have so far advanced, before the arrival of the medical attendant, that the patient could not swallow, might not the emetic tartar, dissolved in some bland liquid, as barley water, be injected into the bowels, by means of Reed's syringe; or, in solution in warm water, into the veins, by means of Anel's, with advantage; allowing, in the latter case, as much blood to flow from a vein in one arm, as warm solution was injected into one of the other.

Or, if the patient was of a strong full habit, the abstraction of blood from the arm to syncope, assisted by the use of the warm bath. would probably give us a chance of administering the medicine by the mouth.

With regard to the local treatment, $I$ think the excision, or cauterization of the bitten part might be practised with advantage, even after the constitutional symptoms have commenced ; for, since it is a fact that weeks, or even months may elapse, between the receipt of the injury, and the constitution becoming affected, may not the poison remain during that time in the bitten part, and then generate matter equally deadly in its effects, from which the disease is afterwards fed? 'That the poison enters the system immediately and there remains inactive, even for months, appears to me exceedingly improbable; and, hence, I should have great hopes of rescuing the patient by a careful excision and cauterization of the injured parts, at any period between their receipt and the alteration in the appearance of the cicatrix, which is the first symptom of the constitution becoming affected. May not this treatment be applied to a certain extent in tetunus, between which and the disease in question there is a very striking analogy; each appearing to be seated principally in the nervous system.

By giving place to these hnts, in an early Number of your very usctiul and widelycirculated Journal, Youwill much oblig e, \&c. JoIIN MEDd, Surgeon.

Leyburn, Yorkshire, March :27, 18:8.
ON THE AGENCY OF PRESSURE IN UTERINE IAMORRHA GE.

BY R. IANYON, JUN,, ESQ, SURGEON, LOSTWTTIIEL.

I rive been much amused, by meeting with occasional papers in THE $L_{A}$ CET, respecting pressure as an invention in uterine hæmorrhage. Mr. Hill also smiles at " the tug of war" between those modern combatants for immortality; and $I$, in $m v$ turn, may be allowed to dispute the ground, inch by inch, in farour of Ambrose Parey, unless Mr." Hill is prepared to prove that Dr. Dennison lectured at the London IIospital prior to his time! Pressure, whether by books or bandage, is pressure still; it matters but little, in the investigation, how the principle be applied. The question is, who first recommended pressure in any form, to arrest or prevent the accession of uterine hæmorrhage? Clearly, neither Mr. Searle nor Dr. W. Dennison, nor indeed do I claim it for Ambrose Parey, but certainly he says of the woman, after delivery has been accomplished, "let her bellie bee also bound or rowled with a ligature of an indifferent breadth and length, which may keep the cold air from the womb, and also press the biood out that is contained in all the substance thereof."* I am not angry that Dr. W. Dennison taught the propriety of using pressure " in all labours, $f$ " but am only desirous of recording, that Ambrose Parey inculcated the same thing, more than two hundred years ago. He certainly does not say positively that he applied it with that intention, but I am of opinion that be who would recommend a bandage immediately after delivery, to press hlod from the womb, could never be ignorant of its utility in arresting uterine hæmorrhage, any more than he who grasps the abdomen for the purpose of inducing sepation of the placenta, would neglect the use of the sume means in flooding; or, that he who from necessity introduces his hand into the uterus to detach the placenta, should be so far ignoraut of the principle, as not to do so in cases of uterine hemorrhage. For when the acconchear grasps the abdomen, his indication is to overcome torpidity of the uterus,and it is done with the view of exciting contraction of its fibres. The extension of

* The workes of that famous chirurgeon Ambrose Parey, translated by $J_{0 h n s o n}$ p. 615.

+ See Lancer for Nov. 17, 1897, p. $26 \%$ 